\title{
Solid-state MAS NMR, TEM, and TGA studies of structural hydroxyl groups and water in nanocrystalline apatites prepared by dry milling
}

\author{
Lukasz Pajchel • Waclaw Kolodziejski
}

Received: 18 November 2012/ Accepted: 15 July 2013/Published online: 30 July 2013

(C) The Author(s) 2013. This article is published with open access at Springerlink.com

\begin{abstract}
A series of nanocrystalline calcium hydroxyapatites was prepared by dry milling and characterized using proton and ${ }^{31} \mathrm{P}$ MAS NMR, TEM, and TGA methods. The samples contained stubby rodshaped crystals, which length and width varied in the 130-30 and 95-20 $\mathrm{nm}$ ranges, respectively. It was confirmed that concentration of structural hydroxyl groups in nanocrystalline apatites decreases with the decreasing crystal size. In the series of the studied apatites, the decrease was from 86 to ca. $50 \%$ in reference to stoichiometric apatite. Water was found in the surface hydrated layer and in the $c$-axis channels, in which compartments existed as adsorbed and structural, respectively. Molecules of the adsorbed water were capable of moving from the crystal surface into the lattice $c$-axis channels of apatite. This process introduced considerable structural disorder within and around those channels and reduced the content of the structural hydroxyl groups, particularly in the region underneath the apatite crystal surface.
\end{abstract}

Electronic supplementary material The online version of this article (doi:10.1007/s11051-013-1868-y) contains supplementary material, which is available to authorized users.

L. Pajchel · W. Kolodziejski ( $\square)$

Department of Inorganic and Analytical Chemistry,

Faculty of Pharmacy, Medical University of Warsaw,

ul. Banacha 1, 02-097 Warsaw, Poland

e-mail: waclaw.kolodziejski@wum.edu.pl
Keywords Apatite $\cdot$ Milling $\cdot$ Nanocrystals · Hydroxyl groups $\cdot$ Structural water $\cdot$ NMR

\section{Introduction}

Hydroxyapatites (HA) are minerals of great geological, biological, and medical importance (Aoki 1991; Dorozhkin 2009, 2010; Eichert et al. 2009; Elliott 1994; LeGeros 1991; Olszta et al. 2007). Stoichiometric calcium hydroxyapatite, $\mathrm{Ca}_{10}\left(\mathrm{PO}_{4}\right)_{6}(\mathrm{OH})_{2}$, is the reference mineral in the studies of synthetic and biological apatites. Generally, apatites are non-stoichiometric, although they keep the same crystal space group $\mathrm{Pb}_{3} / \mathrm{m}$. They are prone to various ionic substitutions in the crystal lattice, which substantially affect their physicochemical properties and biological behavior.

The HA mineral of mammal bone, dentin, and dental cementum is nanocrystalline. It is formed of prolate platelet crystals, which are 30-50 nm long, 15-30 nm wide, and 2-10 nm thick (Dorozhkin 2009, 2010). Because of the nanosize of those crystallites, their surface and interior are considerably interrelated, which circumstance gives the material unique properties. Such biological HA contains 3-9 wt $\%$ of $\mathrm{CO}_{3}{ }^{2-}$ ions, preferably substituted for $\mathrm{PO}_{4}{ }^{3-}$ ions in so-called B-sites (Aoki 1991; Dorozhkin 2009, 2010; Eichert et al. 2009; Elliott 1994; LeGeros 1991; Olszta et al. 2007). The nanocrystals are covered by a hydrated 
layer, which accommodates ionic non-apatitic environments (Bertinetti et al. 2007; Bertinetti et al. 2008; Cazalbou et al. 2004; Jäger et al. 2006a, b; Kaflak and Kolodziejski 2008; Ramirez et al. 2009; Rey et al. 2007; Rey et al. 2009; Sakhno et al. 2010; Wilson et al. $2005,2006)$. This layer is $1-2 \mathrm{~nm}$ deep and encompasses $40-55 \%$ of phosphorus present in the material. Some researchers assume this region to be structured, while others describe it as amorphous. The hydrated layer participates in an ionic exchange and serves as a functional interface between mineral and proteinaceous compartments of hard tissues.

In the HA crystal lattice there are $0.30-0.35 \mathrm{~nm}$ wide channels, running along the crystal $c$-axis. They can be occupied by structural hydroxyl groups $\left(\mathrm{OH}^{-}\right.$ ions) (Aoki 1991; Elliott 1994; LeGeros 1991), other small ions as $\mathrm{F}^{-}, \mathrm{Cl}^{-}, \mathrm{CO}_{3}{ }^{2-}$ (the latter species called A-type carbonates) (Aoki 1991; Elliott 1994; LeGeros 1991) and structural water (Ivanova et al. 2001; Mason et al. 2009; Nordström and Karlsson 1990; Wilson et al. 2005, 2006; Yoder et al. 2012a, b). In stoichiometric HA, those channels contain only the hydroxyl groups, organized in the $\cdots \mathrm{O}-\mathrm{H}$ O-H O-H O-H $\cdots$ columns. The consecutive hydroxyls are too distant from each other to form hydrogen bonds (the $\mathrm{O}-\mathrm{O}$ distance of $3.44 \AA$ ). Therefore, their proton NMR peak recorded under magic-angle spinning (MAS) appears at $0.0 \mathrm{ppm}$ (Kolodziejski 2005). Carbonated HA of bone mineral contains only ca. $21 \%$ of the structural hydroxyl groups, normally present in the stoichiometric HA (Cho et al. 2003). For dental enamel, dentin, and dental cementum, the respective values are 73, 18, and $18 \%$ (Kolmas and Kolodziejski 2007). Pasteris et al. (2004) and Wopenka and Pasteris (2005) proposed an interesting explanation of those $\mathrm{OH}^{-}$ deficiencies in apatites. They postulated that the smaller the crystallite size, the greater is atomic disorder within crystal unit cells and the less energetically favorable it is for apatite to incorporate $\mathrm{OH}^{-}$ into its channel sites.

In this work, our primary objective was to verify experimentally that hypothesis using a series of nanocrystalline apatites with decreasing mean crystal sizes, prepared by dry milling of the same parent material. As far as we know, a relationship between structural hydroxyl groups and surface hydrated layer has been studied for the first time. Mechanochemical synthesis, activation, and modification of HA have already been investigated (Abdel-Aal et al. 2008;
Bignon et al. 2002; Chaikina and Aman 2005; Isobe et al. 2002; Mohammadi Zahrani and Fathi 2009; Nakano et al. 2001; Nasiri-Tabrizi et al. 2009; Nilpairach 1997; Ruksudjarit et al. 2008). However, solidstate NMR has been used only once in mechanochemistry of apatites, that is, to characterize HA prepared by a wet-mechanochemical reaction (Isobe et al. 2002). We employed ${ }^{1} \mathrm{H}$ and ${ }^{31} \mathrm{P}$ MAS NMR to study drymilled samples as a function of the milling time and crystal size. The proton peaks at 0.0 and 5.4 ppm were applied to quantify structural hydroxyl groups and water, respectively. Cross-polarization (CP) from the hydroxyl and water protons was used to analyze a complex ${ }^{31}$ P MAS NMR line at $3.1 \mathrm{ppm}$. Components of that line allowed us to monitor the crystal interior and the crystal surface. Dependencies of various physicochemical properties on the crystal size have been also examined and discussed.

\section{Materials and methods}

Samples and their characterization

The foremost parent hydroxyapatite designated HA0 was purchased from Berkeley Advanced Biomaterials, Inc. (BABI-HAP-SP; agglomerated sphere-like dry powder, average particle size of ca. $5 \mu \mathrm{m}$ and the $\mathrm{Ca} / \mathrm{P}$ ratio of 1.67 , as declared by the supplier). According to our later examination using transmission electron microscopy (TEM), the particles were formed of ca. $100 \mathrm{~nm}$ crystals. This material lost ca. 0.19 and 0.32 wt $\%$ in the $25-200$ and $200-550{ }^{\circ} \mathrm{C}$ temperature ranges, respectively (TGA using SDT Q600 V20.9 Build 20 of TA Instruments; measured in argon, $10 \mathrm{mg}$ samples, heating rate of $5 \% \mathrm{~min}$, no thermal pretreatment before performing the TGA analyses). Those quantities correspond to adsorbed water and structural water, respectively (Yoder et al. 2012a, b), giving HA0 the total water content of $0.51 \mathrm{wt} \%$.

HA0 was subjected to dry milling in a vibrational ball mill (Testchem; LMW-S) for a specified period of time $t$ in order to obtain apatites with various mean crystal sizes. Accordingly, the milled samples have been designated HA $t$, where $t$ is given in hours. The milling was done in tungsten carbide vessels using tungsten carbide $12 \mathrm{~mm}$ balls. Each milling session to produce particular HA $t$ started from $1 \mathrm{~g}$ of HA0. After every hour of processing, the procedure was 
interrupted for $1.5 \mathrm{~h}$ in order to cool down the device (no breaks for HA0.25, HA0.5, and HA1).

It has been checked using powder X-ray diffraction (PXRD; Bruker D8 Discover), that the HAt samples were homogenous and contained only apatite. As well, their ${ }^{1} \mathrm{H}$ and ${ }^{31} \mathrm{P}$ MAS NMR spectra were typical of HA (vide infra). PXRD was also used to determine a crystallinity parameter according to Landi et al. (2000). As the milling operation was done in the air atmosphere (external temperature at $298 \mathrm{~K}$, humidity of ca. $40 \%$ ), the material was allowed to absorb ambient $\mathrm{CO}_{2}$ and to undergo $\mathrm{CO}_{3}{ }^{2-}$ substitutions for $\mathrm{PO}_{4}{ }^{3-}$ groups (type-B carbonates) or for structural $\mathrm{OH}^{-}$groups (type-A carbonates). The contents of the $\mathrm{A}$ and $\mathrm{B}$ carbonates were estimated using the infrared method of Sønju Clasen and Ruyter (1997) and (Kaflak et al. 2011). Spectroscopic FT-IR studies were carried out at $298 \mathrm{~K}$ on a Perkin Elmer Spectrum 1000 spectrometer. The absorption spectra were acquired with $2 \mathrm{~cm}^{-1}$ spectral resolution from $\mathrm{KBr}$ pellets using a mercury cadmium telluride (MCT) detector and 50 scans. They were processed using the GRAMS/AI 8.0 software (Thermo Scientific, 2006). The processing included baseline correction, offset correction, and peak fittings.

Apatite crystals (non-sintered) were observed using TEM (JEOL JEM 1400 equipped with the EDX accessory). For this purpose, a drop of a sample suspension in ethanol (without prior ultrasonication) was placed on a Ni grid covered with a Formvar film, allowed to dry and analyzed under the accelerating voltage of $80 \mathrm{kV}$. Averaged crystal sizes were calculated from at least 310 randomly selected 2D crystal images using the STATISTICA 64 software (Version 10, StatSoft, Inc. 2011). The electron diffraction studies were done on a JEOL TEM microscope (JEM 2000EX). The diffraction images were recorded on a photographic film and then converted to digital images with a NIKON LS-8000 scanner. The sample suspension in methanol was ultrasonicated over $45 \mathrm{~min}$ and then a drop of this suspension was placed on a $\mathrm{Cu}$ grid covered with a carbon film, allowed to dry and analyzed using an electron beam with energy of $200 \mathrm{keV}$.

The HA 0 crystals were observed in the $3 \mathrm{D}$ mode by electron tomography using a JEM 1400 (Jeol Co.,) microscope at $80 \mathrm{kV}$ with a tilt-rotate tomographic holder and a high-resolution digital camera (CCD MORADA; Olympus Soft Imaging Solutions,
Germany). The images were taken at 60,000 magnification from $55.4^{\circ}$ to $-55^{\circ}$, in steps of $0.82^{\circ}$. The series of 134 images with the defined common axis of rotation was exported in TIFF (multi-page). The latter format was then converted into AVI using ImageJ software (National Institutes of Health, Bethesda, MD, USA).

Agglomerates of apatite crystals were observed using NovaNano SEM 450 electron microscope (FEI), equipped with the EDAX accessory (Apex/Genesis XM 2 with an Apollo XL SDD detector). The apatite powder was fixed to an adhesive conducting tape and then analyzed under the accelerating voltage of $5 \mathrm{kV}$.

The physicochemical characteristics of the studied samples are presented in Table 1. Representative PXRD diffractograms and FT-IR spectra are shown in Online Resource 1.

\section{NMR experiments}

High-resolution solid-state ${ }^{1} \mathrm{H}$ and ${ }^{31} \mathrm{P}$ NMR spectra (Bruker Avance 400WB; $400 \mathrm{MHz}$ for ${ }^{1} \mathrm{H} ; 160 \mathrm{MHz}$ for ${ }^{31} \mathrm{P}$ ) were acquired with MAS at $12 \mathrm{kHz}$ for ${ }^{1} \mathrm{H}$, and 7 and $3.5 \mathrm{kHz}$ for ${ }^{31} \mathrm{P}$. The rotors were spun by dry air at $298 \mathrm{~K}$. The conventional $\pi / 2$ pulse-acquire (Bloch-decay, BD) and $\mathrm{CP}$ spectra were measured using a Bruker $4 \mathrm{~mm}$ probe. The ${ }^{1} \mathrm{H}$ BD/MAS NMR experiments were done with a $\pi / 2{ }^{1} \mathrm{H}$ pulse of $2.9 \mu \mathrm{s}$, 32 scans and a repetition time of $30 \mathrm{~s}$. The proton background of the probe was carefully subtracted (Chen et al. 2004). The ${ }^{31} \mathrm{P}$ CP/MAS NMR experiments were done with a $\pi / 2{ }^{1} \mathrm{H}$ pulse of $2.65 \mu \mathrm{s}$, a contact time of $2 \mathrm{~ms}, 64$ scans and a repetition time of $5 \mathrm{~s}$.

The ${ }^{31} \mathrm{P}$ CP/MAS NMR signal was also recorded with a specific selection of water or structural $\mathrm{OH}$ groups as the proton polarization source. This was done by appropriate preparation of the proton reservoirs before CP. Water was well selected by a presaturation comb of proton pulses followed by a properly adjusted relaxation delay, which pulse chip preceded the normal CP pulse sequence on the proton channel. That introductory segment of the modified $\mathrm{CP}$ pulse sequence worked similarly to the conventional saturation recovery experiment performed on proton spins and took advantage of shorter $T_{1}$ of the water protons comparing to that of the intracrystalline $\mathrm{OH}$ protons. Structural $\mathrm{OH}$ groups were selected by an extra proton lock of $15 \mathrm{~ms}$, which was introduced 
Table 1 Physicochemical characteristics of the HA0-HA36 samples

\begin{tabular}{|c|c|c|c|c|c|c|c|}
\hline \multirow[t]{2}{*}{ Sample } & \multicolumn{2}{|c|}{$\begin{array}{l}\text { Mean crystal } \\
\operatorname{size}^{\mathrm{a}}(\mathrm{nm})\end{array}$} & \multirow[t]{2}{*}{$\begin{array}{l}\text { Crystallinity } \\
\text { index }^{\mathrm{b}}\end{array}$} & \multirow[t]{2}{*}{$\begin{array}{l}\text { TGA weight } \\
\operatorname{loss}^{c}(\text { wt } \%)\end{array}$} & \multirow[t]{2}{*}{$\begin{array}{l}\text { B carbonates } \\
(\mathrm{wt} \%)\end{array}$} & \multirow[t]{2}{*}{$\begin{array}{l}\text { Structural OH } \\
\text { content }^{\mathrm{e}}\end{array}$} & \multirow[t]{2}{*}{$\begin{array}{l}\text { Relative water } \\
\text { content }^{\mathrm{e}}\end{array}$} \\
\hline & Length & Width & & & & & \\
\hline HA0 & 129 & 95 & 94 & 0.51 & 0.49 & 86.4 & 100 \\
\hline HA0.25 & 97 & 71 & ND & ND & 0.46 & 86.8 & 99 \\
\hline HA0.5 & 81 & 61 & ND & ND & 0.58 & 85.6 & 122 \\
\hline HA1 & 82 & 58 & ND & ND & 0.54 & 85.6 & 217 \\
\hline HA2 & 85 & 62 & ND & ND & 0.57 & 80.8 & 246 \\
\hline HA3 & 56 & 44 & 84 & 1.75 & 0.61 & 78.3 & 341 \\
\hline HA4 & 55 & 40 & ND & ND & 0.58 & 75.8 & 311 \\
\hline HA5 & 56 & 44 & ND & ND & 0.63 & 67.3 & 365 \\
\hline HA6 & 63 & 44 & 75 & 2.65 & 0.59 & 66.5 & 329 \\
\hline HA12 & 42 & 32 & 65 & 3.66 & 0.69 & 60.6 & 487 \\
\hline HA24 & 35 & 26 & 58 & 4.50 & 0.96 & 50.8 & 616 \\
\hline HA36 & 23 & 20 & 61 & 3.78 & 0.90 & 53.2 & 957 \\
\hline
\end{tabular}

a TEM (see Materials and methods and Online Resource 1)

b From PXRD (Landi et al. 2000)

c In the $25-550{ }^{\circ} \mathrm{C}$ temperature range

d From IR (Kaflak et al. 2011; Sønju Clasen and Ruyter 1997)

e From proton MAS NMR

before the contact pulse on the proton channel (Kaflak and Kolodziejski 2008; Kolodziejski 2005). Such experiment was capable of eliminating the magnetization of the water protons, since their $T_{1 \rho}$ was much shorter than that of the structural $\mathrm{OH}$ protons.

Relative contents of structural $\mathrm{OH}$ groups and water were determined by fitting the 0.0 and 5.4 ppm proton lines, respectively, followed by comparing their areas to those of appropriate standards. The calculations involved sample weights. The measurements for the studied samples and standards were done using the same BD pulse sequence, MAS rate, and NMR parameters. The probe tuning required only a minor correction for the next apatite sample. As the $\mathrm{OH}$ standard, we used the HA800 sample from the former work (Kolmas and Kolodziejski 2007) (calcined at $800{ }^{\circ} \mathrm{C} ; 94 \pm 1 \%$ of $\mathrm{OH}$ by reference to stoichiometric HA). The relative water content was determined by reference to the parent apatite HA0.

The peak fittings were done using the NutsPro (Acorn NMR 2007) and ACD SpecManager (Version 10.08, Advanced Chemistry Development, Inc., 2007) computer programs. Figures were prepared using the KaleidaGraph computer program (Version 3.5 for PC, Synergy Software, 2000).

\section{Results and discussion}

General characteristics of the milled apatites

On the bright field TEM micrographs, 2D images of the HA0-HA36 crystals had prolate plate-like shapes and nanodimensions (Fig. 1a-c). Those dimensions were determined for single, well-separated crystals or well-seen crystals belonging to small grains, selected from many TEM micrographs to satisfy random sampling requirement. In manual treatment (Higgins 2000), a selected 2D crystal image was analyzed to find its maximum length and orthogonal width with a measure IT program (Version 5.1, Build 2067) of Olympus Soft Imaging Solutions $\mathrm{GmbH}$. Then, those characteristics were employed as measures of the true crystal length and width, respectively. The validity of this procedure will be discussed later. The crystals had strong tendency to agglomeration, as shown using SEM (Fig. 1d-f). According to the electron diffraction (Fig. 1g), the studied samples were polycrystalline and contained apatite with a hexagonal crystal structure. Moreover, no admixed crystalline phases were found using PXRD (Online Resource 1). The 
dark field TEM images demonstrated variation of sizes and shapes of the material nanoparticles (Fig. 1h).

We were also interested in true 3D habits of the apatite crystals. For HA0 (the largest crystals), it was feasible to acquire electron tomography movie (Online Resource 2). This revealed stubby rodshaped crystals. The chunky rods with rounded terminations were also visible on the SEM micrographs of the HA0-HA36 samples (Fig. 1d-f). Thus, the similar 3D shape was maintained in the series of our samples, which circumstance rendered the length-to-width aspect ratio almost invariant to the milling time ( $1.33 \pm 0.02$, cf. Table 1 ; Fig. 2$)$. The latter effect is also consistent with the fractal theory of material fragmentation by crushing, grinding, blasting, and so on (Turcotte 1986). In our case, apatite particles obtained by dry milling probably follow a self-similar (fractal) size distribution (Glazner and Mills 2012).

During the analysis of the TEM micrographs one is confronted with the stereological problem of using 2D projection (section) data to construct 3D crystal size distributions (Higgins 2000; Royet 1991). For the stereological data treatment, both the cut-section effect and the intersection-probability effect have to be operative (Higgins 2000). Those requirements are not fulfilled in our work. In fact, we found no indications in the electron diffractograms of a specific crystal alignment, e.g., no oblique texture electron diffraction pattern. However, our crystal selection procedure for the TEM analysis was focused on individual crystals, which should rather have tendency to deposit their rods parallel to the Formvar film.
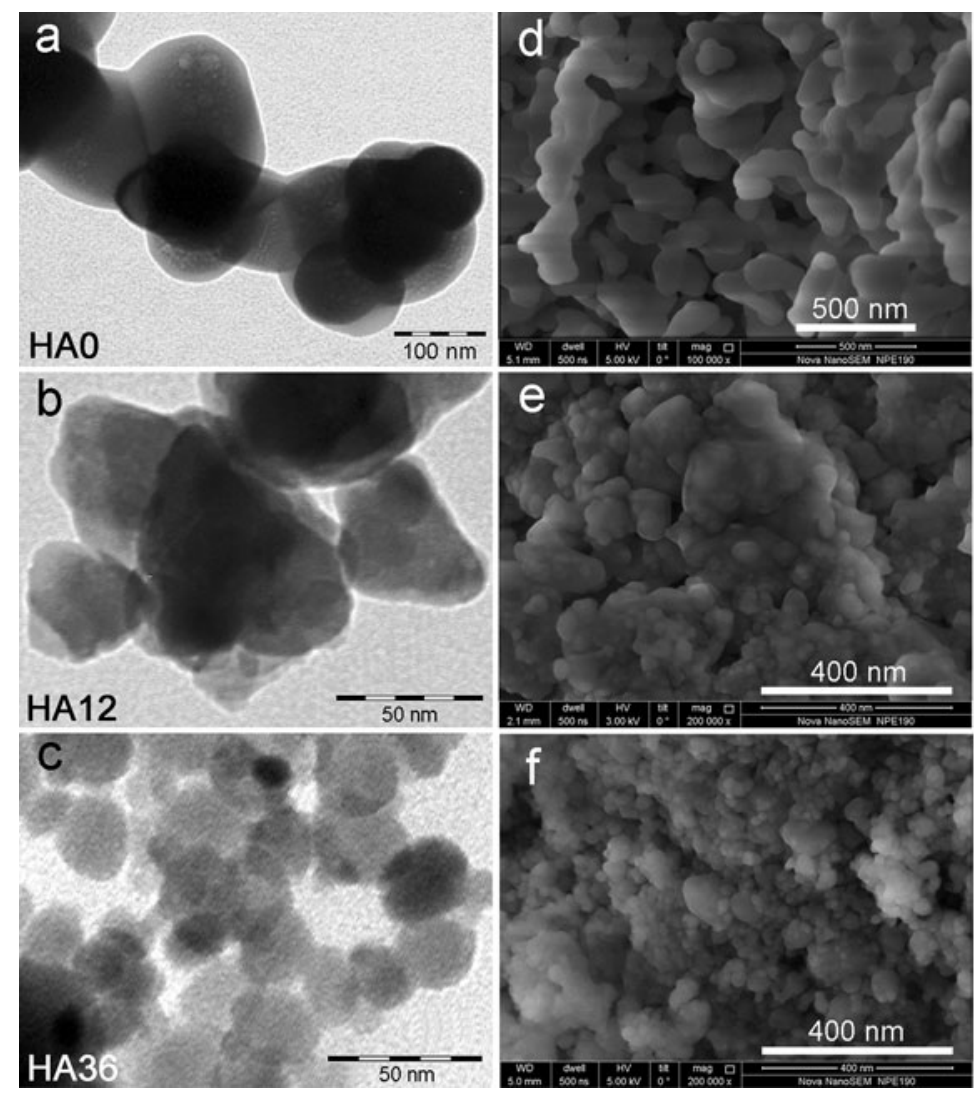
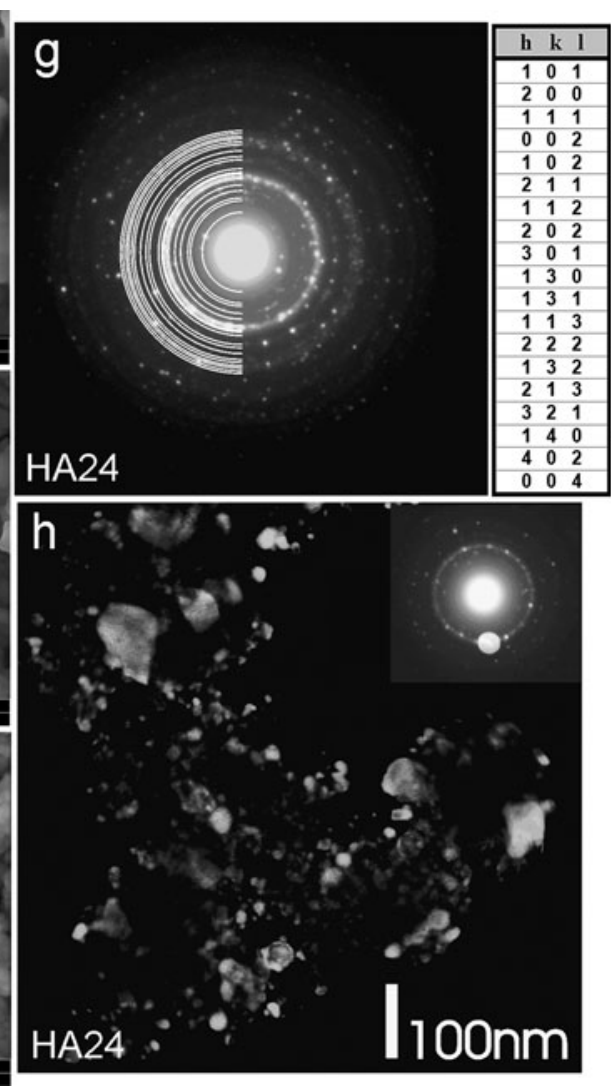

Fig. 1 The morphology and crystallinity of the studied apatites: a-c representative TEM micrographs; $\mathbf{d}-\mathbf{f}$ representative SEM micrographs; $\mathbf{g}$ electron diffractogram of HA24 (left) with Miller indices (right) assigned to the diffraction rings and listed from the pattern center; $\mathbf{h}$ a dark field image of HA24 formed from the strongest reflections: (2 $\left.\begin{array}{lll}2 & 1\end{array}\right)$ and ( $\left.\begin{array}{lll}1 & 1 & 2\end{array}\right)$ (see the upperright inset). The parameters of the hexagonal unit cell of HA24, determined from the electron diffraction: $a=0.9424(4) \mathrm{nm}$, $c=0.6879(4) \mathrm{nm}$ 
Fig. 2 The crystal size distributions and mean crystal dimensions for the studied apatites: a stacked lognormal distributions of crystal lengths and widths in HA24; $b$ the dependence of the scale parameter of the lognormal distribution on the mean crystal dimensions of various samples; $\mathbf{c}$ the dependence of the mean crystal dimensions and the length/width aspect ratio on the milling time. The curves in the parts $\mathbf{b}$ and $\mathbf{c}$ are only guides for eyes
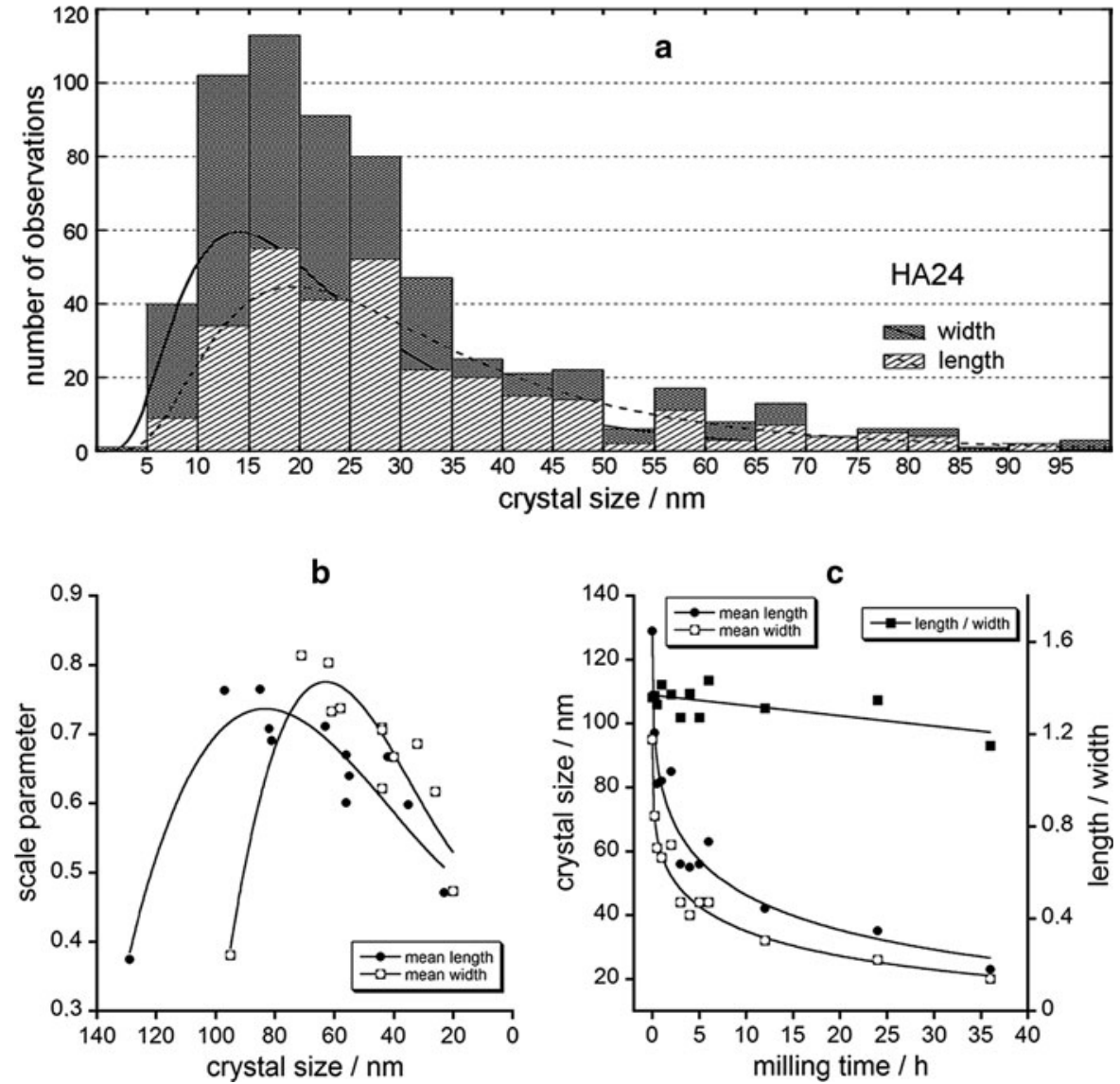

Therefore, we infer that the crystal length and size values obtained from the $2 \mathrm{D}$ images are sound measures of the corresponding 3D structural parameters. Anyway, we had to rely on those values, because there are no dependable stereological procedures for rod-shaped crystals to obtain true 3D structural parameters from their 2D counterparts. Furthermore, for a preferable alignment the conventional stereological data processing fails.

For each sample, the distributions of the TEMdetermined crystal length and width were lognormal (Fig. 2a). In the lognormal distribution, the scale parameter $\sigma$ is the standard deviation of the data set after the normal-logarithmic transformation. The lognormal distribution is skewed right, and the skewness increases as the value of $\sigma$ increases. The skewness of our distributions of crystal dimensions steeply increased at the beginning of milling, reaching maximum $\sigma$ for HA0.25-HA0.5, and then decreased with the decrease of the crystal size
(Fig. 2b). The mean crystal dimensions decreased on milling (Fig. 2c), especially during first $5 \mathrm{~h}$ of grinding. After $36 \mathrm{~h}$ milling, the crystal size decreased from ca. $100 \mathrm{~nm}$ to ca. $20 \mathrm{~nm}$, while the crystallinity assessed by the PXRD index (2000) went down from 94 to ca. $60 \%$ (Table 1). The BET surface area increased from 5 to $46 \mathrm{~m}^{2} \mathrm{~g}^{-1}$. Our parent apatite HA0 contained ca. 0.5 wt $\%$ of B carbonates. On milling, their concentration increased to ca. 1.0 wt $\%$ for HA24 and HA36, as estimated from the $1,415 \mathrm{~cm}^{-1}$ IR band (Kaflak et al. 2011; Sønju Clasen and Ruyter 1997). For all studied samples, the content of A carbonates was immaterial (the A/B carbonate ratio below 0.05), as estimated from the $1,544 \mathrm{~cm}^{-1}$ IR band (Kaflak et al. 2011; Sønju Clasen and Ruyter 1997). The concentrations of structural $\mathrm{OH}$ groups and water decreased and increased with the milling time, respectively (Table 1), and those findings will be of our particular concern in the following discussion. 
Interpretation of the NMR spectra

The proton MAS NMR spectra of the milled apatites (Fig. 3a) contain two signals at 0.0 and $5.4 \mathrm{ppm}$ from structural hydroxyl groups and water, respectively (Kolodziejski 2005). Water resonating at $5.4 \mathrm{ppm}$ has diverse nature. It can be adsorbed and structural. The corresponding ${ }^{1} \mathrm{H}$ chemical shift is characteristic of hydrogen bonded water. It follows that molecules of the structural water, residing in the $c$-axis channels, form hydrogen bonds among themselves and with hydroxide ions, as it was reported by Wilson et al. (2006). Molecules of the adsorbed water are dissimilar in terms of molecular interactions. They can be coordinated to surface $\mathrm{Ca}^{2+}$-sites or can form hydrogen bonds with surface $\mathrm{P}-\mathrm{OH}$ and $\mathrm{P}=\mathrm{O}$ sites, and all of them can participate in hydrogen bonding with neighboring water molecules (Bertinetti et al. 2007; Bolis et al. 2012; Ishikawa et al. 1989; Wilson et al. 2006). The surface species
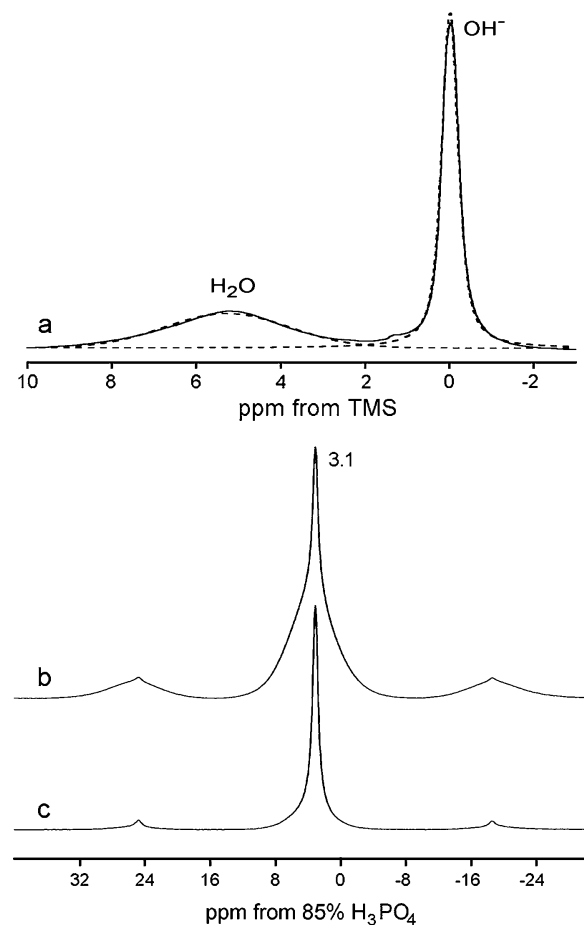

Fig. 3 The exemplary solid-state NMR spectra of the apatite powders, shown for HA24: (a) ${ }^{1} \mathrm{H}$ NMR under MAS at $12 \mathrm{kHz}$; (b) $-(g){ }^{31} \mathrm{P}$ NMR spectra under MAS at $3.5 \mathrm{kHz}$. The graphs (b) and (c) present a comparison of the $\mathrm{CP}$ and $\mathrm{BD}$ spectra, respectively, including first spinning sidebands. Next three spectra were recorded under various preparations of the proton reservoir before $\mathrm{CP}$ (centerbands only shown): $(d)$ a regular are involved in a proton exchange via hydrogen bonds (Kaflak-Hachulska et al. 2003; Kaflak and Kolodziejski 2007, 2011; Kolodziejski 2005), which process controls the shape and chemical shift of the proton line at $5.4 \mathrm{ppm}$.

The ${ }^{31} \mathrm{P}$ MAS NMR spectra of various samples all show a composite signal with a peak position at ca. 3.1 ppm (Fig. 3b, c). That chemical shift is characteristic of apatite (Kolodziejski 2005). A visual inspection of the CP (Fig. 3b) and BD (Fig. 3c) spectra assures that this composite signal comprises at least two overlapped components, probably narrow one at the top of a broad massive line. The latter line is clearly exposed by $\mathrm{CP}$ and gives predominant contribution to spinning sidebands.

The composition of the ${ }^{31} \mathrm{P}$ NMR signal (Fig. 3d) was simply and reliably determined using $\mathrm{CP}$ with an appropriate selection of the polarization source. When polarization was transferred from protons of water, the NMR experiment produced predominantly the broad

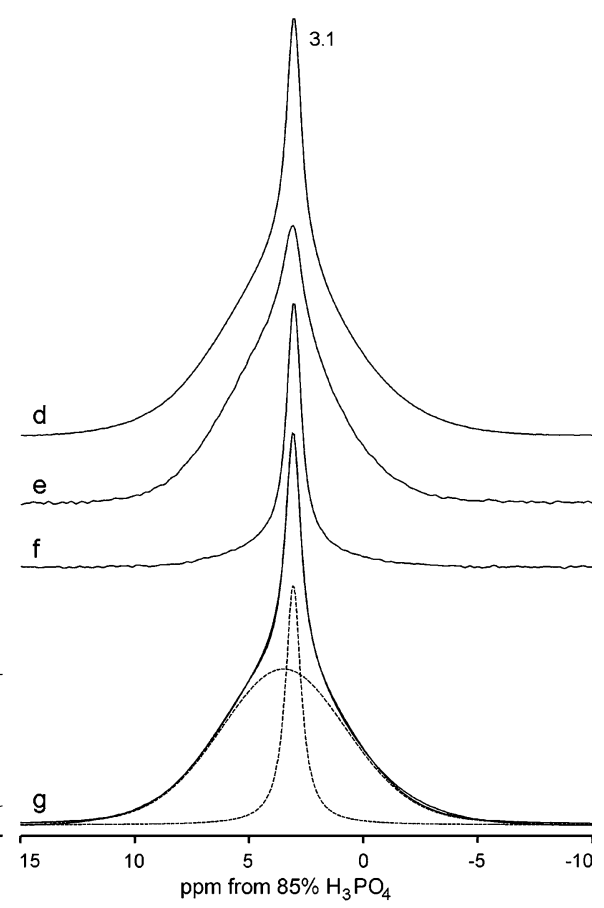

signal; (e) presaturation of protons of structural hydroxyl groups; $(f)$ an extra $15 \mathrm{~ms}$ proton lock before $\mathrm{CP}$ (magnetization of water has been eliminated). In the graph $(g)$, the regular ${ }^{31} \mathrm{P}$ CP line was deconvoluted into two components: a narrow one from the crystal interior (close to the Lorentzian shape) and a broad one from the hydrated layer (Gaussian). The CP spectra were acquired with the $2 \mathrm{~ms}$ contact time 
${ }^{31} \mathrm{P}$ component (Fig. 3e). By contrast, CP from protons of structural $\mathrm{OH}$ groups generated mostly the narrow ${ }^{31} \mathrm{P}$ component. Those discriminating experiments could not give absolutely neat components because of proton spin diffusion between both proton environments. Therefore, we finally evaluated the ${ }^{31} \mathrm{P}$ signal components using peak fittings (Fig. 3g). The mean chemical shifts of the narrow and broad components were found to be $3.10 \pm 0.01$ and $3.65 \pm 0.06 \mathrm{ppm}$, respectively.

The above-mentioned discriminating experiments helped us to assign the broad component to P-sites residing in a water-rich environment and the narrow component to P-sites located close to structural hydroxyl groups. The water-rich environment must be primarily associated with a surface hydrated layer of apatite crystals and possibly can be related to some disordered intracrystalline regions containing water molecules (structural water). The environment of the structural hydroxyl groups can be undoubtedly identified with the crystal interior. The almost pure Gaussian shape of the broad component is indicative of a disorder present in the surface hydrated layer. As concerns the narrow component, it was clearly changing its shape on milling (not shown) from mixed Lorentzian-Gaussian to Gaussian. This NMR effect was probably caused by some influence of the increasing hydrated layer on the crystal interior. We believe that the progressive hydration imposes some structural disorder on the crystal lattice of apatite nanocrystals (vide infra).

The above assignments of the narrow and broad ${ }^{31} \mathrm{P}$ MAS NMR components are in agreement with the former NMR studies of synthetic and biological apatites carried out in our group (Kaflak and Kolodziejski 2008; Kolodziejski 2005). Those studies explained CP kinetics in synthetic, carbonated HA and in bone HA using together two different CP models (Kolodziejski and Klinowski 2002). In the present work, we also found that CP from water, producing here the broad component, conforms to the classical CP model and that CP from structural hydroxyl groups, producing here the narrow component, complies with the nonclassical CP model (Fig. 4). As in the previous studies (Kaflak and Kolodziejski 2008; Kolodziejski 2005), the proton relaxation times in the rotating frame $T_{1 \rho}^{H}$ determined from variable-contact time experiments, were short

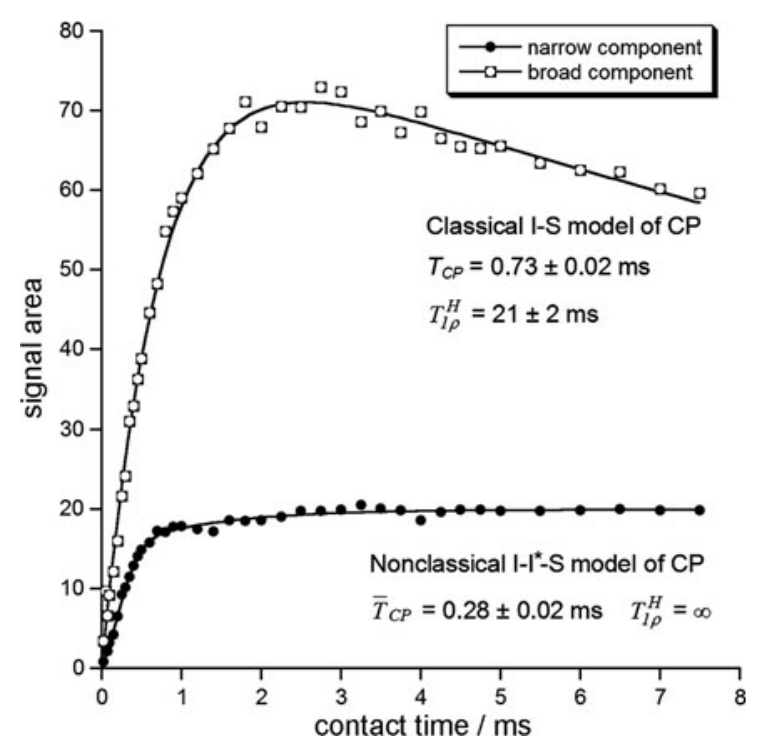

Fig. 4 The dependence of the components of the ${ }^{31} \mathrm{P}$ CP/MAS NMR signal on the contact time (HA24, MAS at $3.5 \mathrm{kHz}$ ). The fitted curves correspond to the nonclassical and classical CP kinetics (Kaflak and Kolodziejski 2008; Kolodziejski and Klinowski 2002; Kolodziejski 2005) for the narrow and broad components, respectively

(21 ms for HA24) and indefinitely long for the classical and nonclassical CP kinetics, respectively.

Hereafter, when discussing the broad component, we shall use $\mathrm{CP}$ results for the optimum contact time of $2 \mathrm{~ms}$ (Fig. 4). Either BD or CP results will be presented to emphasize quantitative or accuracy aspects, respectively. For the same reason, the results obtained under different MAS rates will be selectively considered in the subsequent figures. For MAS at $3.5 \mathrm{kHz}$, the ${ }^{31} \mathrm{P}$ NMR lines were broader, so their linewidths were determined more accurately than for MAS at $7.0 \mathrm{kHz}$. Conversely, the signal areas were less accurate because spinning sidebands had to be included in the signal deconvolutions. But anyway, the complementary remaining results are presented as Online Resource 1.

The interpretation of the ${ }^{31} \mathrm{P}$ MAS NMR spectra requires adequate caution. We submit that the broad component cannot be from ordinary amorphous phosphate (ACP), because ACP gives different ${ }^{1} \mathrm{H}$ and ${ }^{31} \mathrm{P}$ MAS NMR spectra than our milled apatites (Online Resource 1). Powder X-ray diffractograms and FT-IR spectra of the milled samples are typical of fairly crystalline apatites (Online Resource 1). ACP is known to form Posner's clusters (Boskey 1997), 
which give broad diffraction halos and produce a $v_{1}$-phosphate IR band at about $950 \mathrm{~cm}^{-1}$ (Combes and Rey 2010). No such features were found for our samples, even though HA24 and HA36 contained about $30 \%$ of $\mathrm{P}$ in the hydrated layer (vide infra). Nevertheless, the hydrated layer of our milled apatites can still have a different amorphous arrangement to that involving Posner's clusters. There are also other assignments in the literature for extra peaks accompanying the main ${ }^{31} \mathrm{P}$ MAS NMR resonance of apatite. Jarlbring et al. (2006) assigned two weaker shoulder peaks at 5.4 and $0.8 \mathrm{ppm}$ to unprotonated $\equiv \mathrm{PO}_{x}$ and protonated $\equiv \mathrm{PO}_{x} \mathrm{H}$ surface sites in fluoroapatites ( $\equiv$ designates a chemical bond with the HA surface). $\mathrm{Wu}$ et al. (1994) found in bone apatite a signal at $-0.4 \mathrm{ppm}$ from unique $\mathrm{HPO}_{4}{ }^{2-}$ ions. However, our broad component appeared at ca. $3.65 \mathrm{ppm}$ and the aforementioned resonances were absent.

Overall, the proton and ${ }^{31} \mathrm{P}$ MAS NMR peaks from milled apatites have been unequivocally assigned. The proton NMR signals at 0.0 and $5.4 \mathrm{ppm}$ from structural hydroxyl groups and water, respectively, can be used to calculate concentrations of those chemical species. In addition, the narrow (3.10 ppm) and broad (3.65 ppm) components of the ${ }^{31}$ P MAS NMR signal can be employed to monitor environments of structural $\mathrm{OH}$ groups (crystal interior) and of water (crystal surface for adsorbed $\mathrm{H}_{2} \mathrm{O}$ and crystal interior for structural $\mathrm{H}_{2} \mathrm{O}$ ), respectively.

\section{Content and location of water}

The total water content, determined from ${ }^{1} \mathrm{H}$ MAS NMR, increased during milling by one order of magnitude (Table 1). This was caused by a humidity uptake from the surroundings (external temperature at $298 \mathrm{~K}$, humidity of ca. $40 \%$ ). The total water content increased with the decreasing mean crystal length and width (Fig. 5) because of an increasing surface area of crystallites. The corresponding results from TGA indicate an eight- to ninefold increase of the total water content (from 0.5 to 3.8-4.5 wt \%, Table 1), as estimated from the weight loss in the $25-550{ }^{\circ} \mathrm{C}$ temperature range (Yoder et al. 2012a, b). The ${ }^{1} \mathrm{H}$ MAS NMR and TGA results show significant mutual linear correlation $(R=0.9724, p=0.0055$; see Online Resource 1). Hence, they are in good agreement as the total water content is concerned.

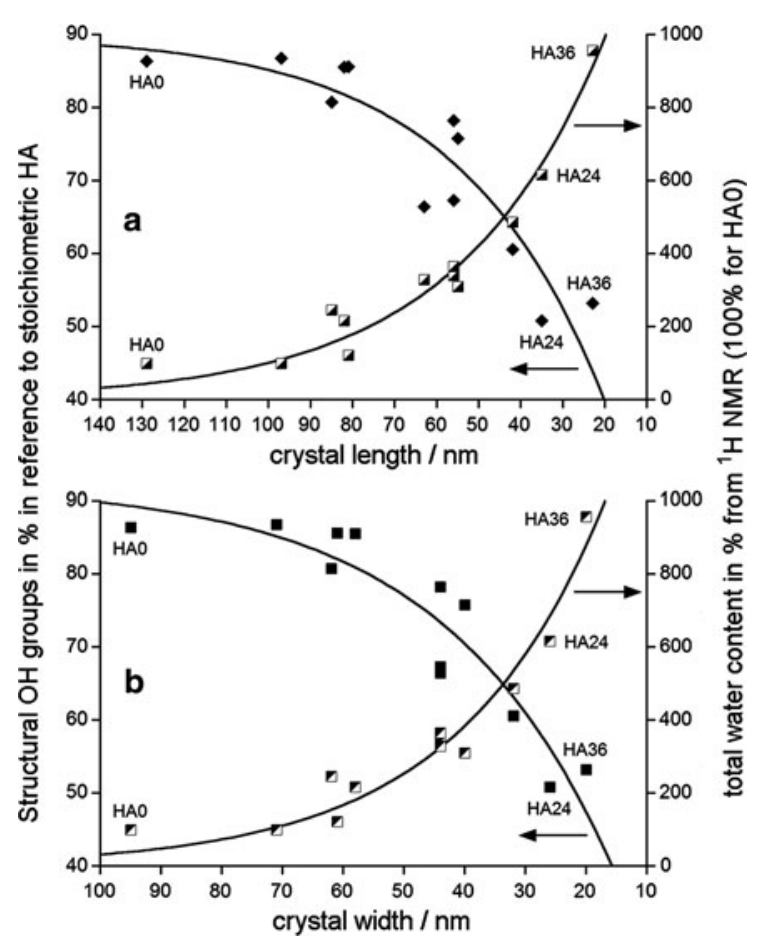

Fig. 5 The dependence of the concentrations of structural $\mathrm{OH}$ groups (in \% in reference to stoichiometric HA) and the total water content (in \%, $100 \%$ for HA0) on the mean crystal dimensions: $\mathbf{a}$ on the crystal length; $\mathbf{b}$ on the crystal width. The $\mathrm{OH}$ and $\mathrm{H}_{2} \mathrm{O}$ concentrations were determined using proton MAS NMR. The exponential curves are only guides for eyes

It has recently been proposed to estimate adsorbed and structural water from TGA weight losses in the 25-200 and $200-550{ }^{\circ} \mathrm{C}$ temperature ranges, respectively (Yoder et al. 2012a, b). Following this interpretation we found using TGA that the contents of the adsorbed and structural water increased on milling and that their ratio increased from 0.6 for HA0 to 2.3 for HA12-HA36 (Fig. 6). Moreover, those concentrations demonstrated a significant positive linear correlation, so that the adsorbed water could be somehow converted to the structural water. A simplest explanation would be that molecules of the adsorbed water are capable of moving from the surface of apatite into its crystal lattice.

Indeed, water molecules from the crystal surface can enter intracrystalline $c$-axis channels used by structural hydroxide ions (Kaflak and Kolodziejski 2008, 2011; Wilson et al. 2006; Yoder et al. 2012a). In the former works from our group (Kaflak-Hachulska 2000; Kaflak and Kolodziejski 2008) it has been postulated that there is probably a proton exchange 


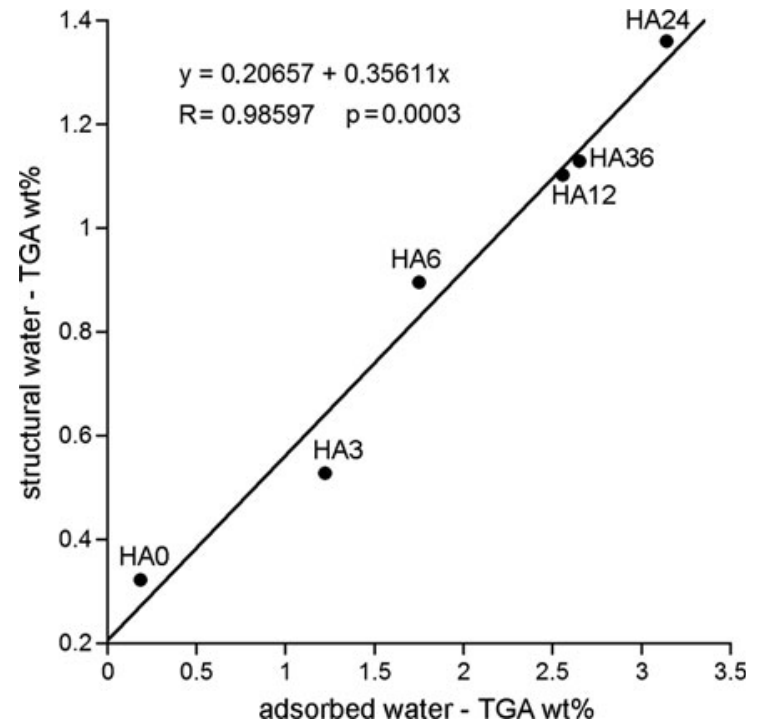

Fig. 6 The relationship between the structural and adsorbed water contents in the milled apatites. The water contents were determined using TGA from the weight losses in the 200-550 and 25-200 temperature ranges $\left({ }^{\circ} \mathrm{C}\right)$, respectively

involving hydroxide ions and water in those channels. Finally, Yoder et al. (2012a) proposed that such process might aid water to get into the crystal lattice channels and that this mechanism could be especially effective at higher temperatures (Yoder et al. 2012a). Since high temperatures are attainable during milling, we suppose that the proton transfer mechanism was in operation for our samples. It was probably supported by physical diffusion of water molecules to fill voids in the $c$-axis channels (Kaflak and Kolodziejski 2008, 2011; Wilson et al. 2006).

Environments of the adsorbed and structural water can be monitored using the broad ${ }^{31} \mathrm{P}$ MAS NMR component. According to our BD studies (Fig. 7a), the broad component corresponded to ca. $30 \%$ of apatite phosphorus for the lowest crystal sizes (HA24 and HA36). It is reminiscent of our CP study of synthetic carbonatoapatite and bone mineral (Kaflak and Kolodziejski 2008), which reported that the surface hydrated layer contained ca. $40 \%$ of apatite phosphorus. In the present work, the broad component area shows significant negative linear correlation with the crystal length and width (Fig. 7a) because the environments of water relatively increase with the decreasing crystal size. Of course, the environments of water increase with the increasing total water content $\left({ }^{1} \mathrm{H} \mathrm{NMR}\right)$ and with the increasing concentration of the adsorbed water (TGA). Those dependencies are confirmed by respective significant linear correlations in Fig. 7b. The relationship with the adsorbed water was chosen because this kind of water was generally more abundant in our samples (Fig. 6).

A rise in the linewidth of the broad ${ }^{31}$ P MAS NMR component can be indicative of a higher disorder in the water environments. Unsuccessfully, the FWHM results for the broad components of the HA0-HA0.5 samples were not sufficiently precise. Therefore, we did not attempt to fit the points in Fig. 7c with a typical sigmoidal activation function (see also Online Resource 1). However, we are convinced of a sharp increase in FWHM for the crystal length of $80 \mathrm{~nm}$ and the crystal width of $60 \mathrm{~nm}$. We believe that for those crystal dimensions the surface hydrated layer began to take form typical of nanocrystalline apatites. The reported crystal dimensions of the hydration transition are probably specific to the milling conditions.

\section{Structural hydroxyl groups}

The content of the structural hydroxyl groups (hydroxide ions in the $c$-axis channels) decreased on milling by ca. $40 \%$ in reference to stoichiometric apatite (Fig. 5). The small increase in B carbonates (Table 1) cannot be responsible for such effect. In terms of the crystal size this decrease occurred in the 130-30 nm range of the crystal length and in the 95-20 $\mathrm{nm}$ range of the crystal width. Thus it was confirmed that the content of the structural $\mathrm{OH}$ groups in nanocrystalline apatites decreases with the decreasing crystal size (Pasteris et al. 2004; Wopenka and Pasteris 2005). We submit that the content of the structural $\mathrm{OH}$ groups did not go down in our samples to the level of ca. $20 \%$, typical of nanocrystalline biological apatite of bone, dentin, and dental cementum. Perhaps, the content of the structural $\mathrm{OH}$ groups in calcified tissues is also biologically controlled during biomineralization.

In order to find a reason of the $\mathrm{OH}$ deficiency for smaller crystallites, we examined relationship between the structural $\mathrm{OH}$ content and appropriate MAS NMR linewidths (Fig. 8a). As before it has been assumed that a broader line indicates a higher disorder. The FWHM value of the proton peak at $0.0 \mathrm{ppm}$ was selected to probe the state of the structural hydroxyl groups. The FWHM value of the narrow ${ }^{31} \mathrm{P} \mathrm{BD}$ component at $3.1 \mathrm{ppm}$ was selected to probe the state of the apatite crystal lattice around the $c$-axis channels 
a

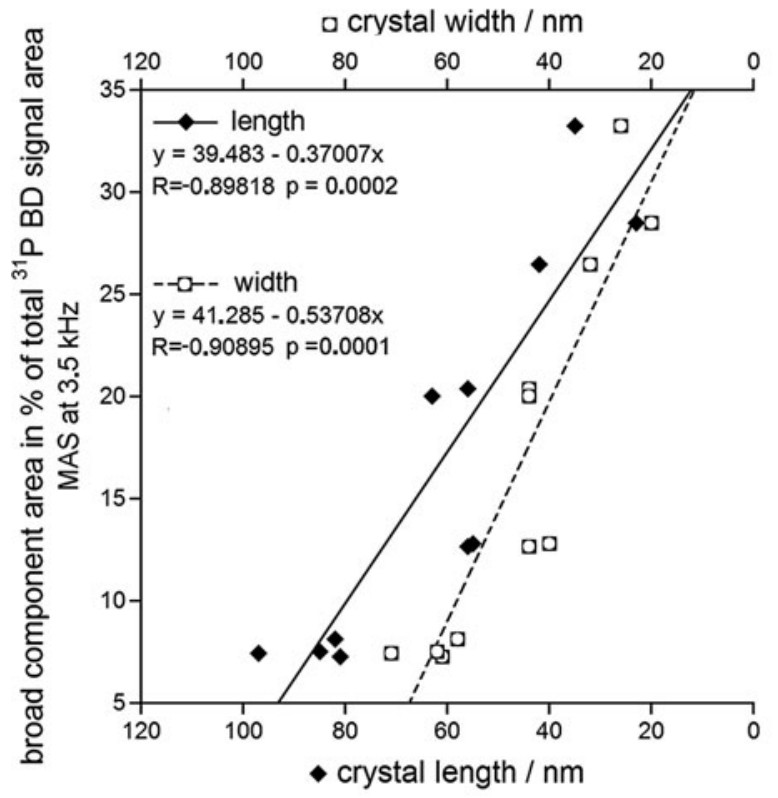

b

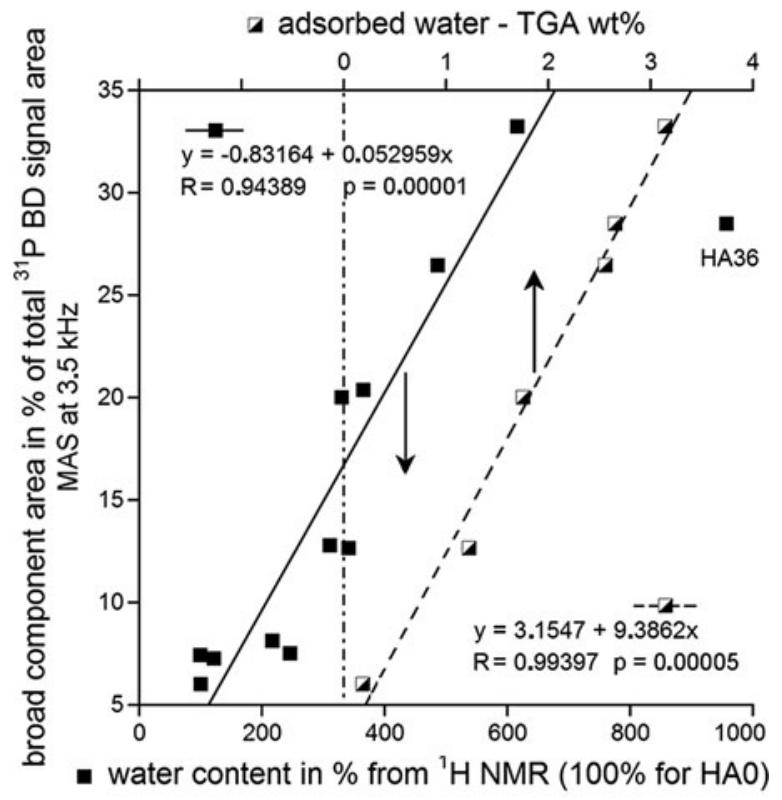

\section{C}

crystal width / nm

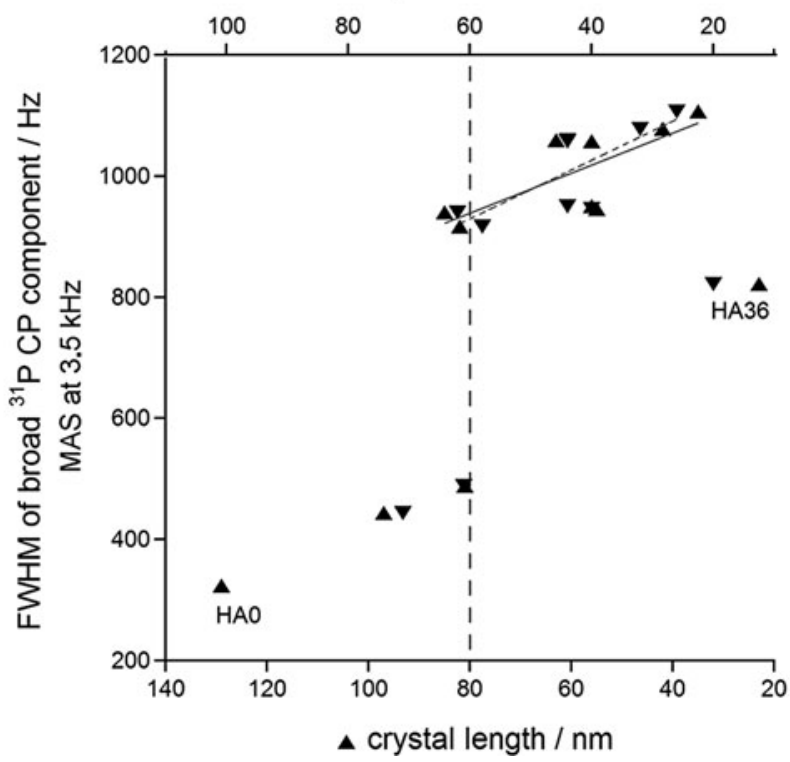

Fig. 7 The parameters of the broad component of the ${ }^{31}$ P MAS NMR signal plotted against various characteristics of the milled apatites: a contribution to the BD spectrum (area in \%) versus mean crystal dimensions; b contribution to the $\mathrm{BD}$ spectrum (area in \%) versus total and adsorbed water contents; c FWHM from the $\mathrm{CP}$ experiment versus mean crystal dimensions. The

containing hydroxide ions of interest and structural water. We found that the structural $\mathrm{OH}$ content decreased with the increase of both FWHM variables experiments were done with MAS at $3.5 \mathrm{kHz}$, first spinning sidebands have been included in the deconvolutions and calculations, CP was performed with the contact time of $2 \mathrm{~ms}$. The total and adsorbed water contents were determined using proton MAS NMR and TGA, respectively

showing significant linear correlations (Fig. 8a). Those correlations can be interpreted as the decrease of the structural $\mathrm{OH}$ content with the growing disorder 


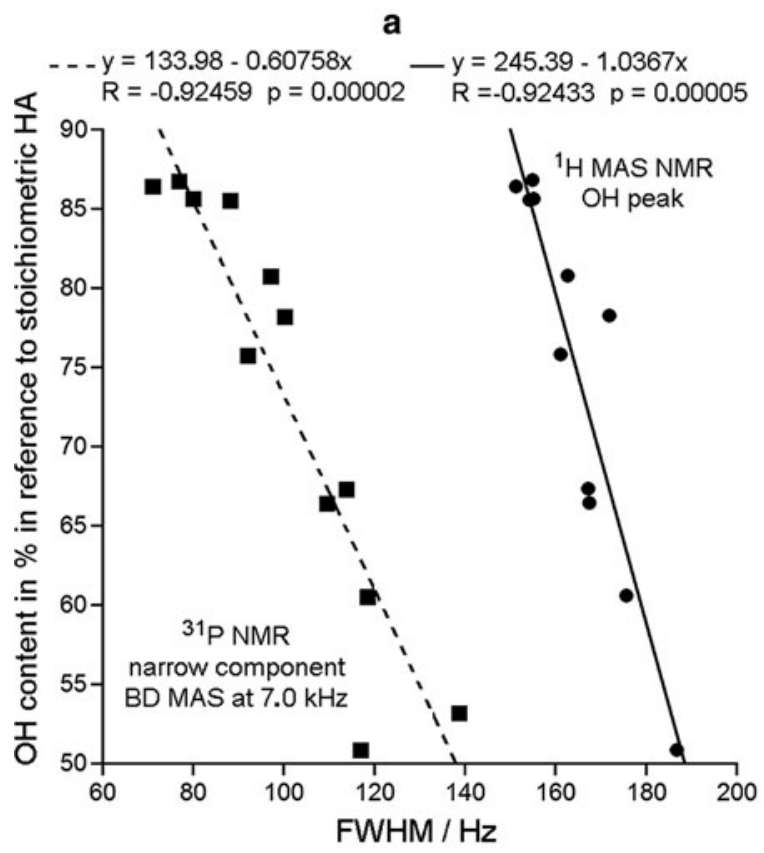

b

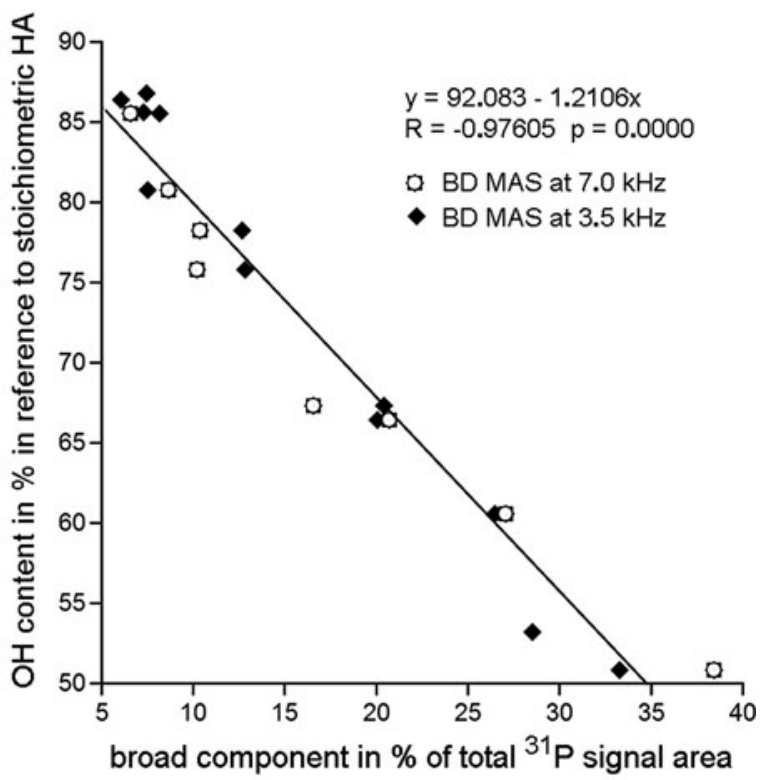

C

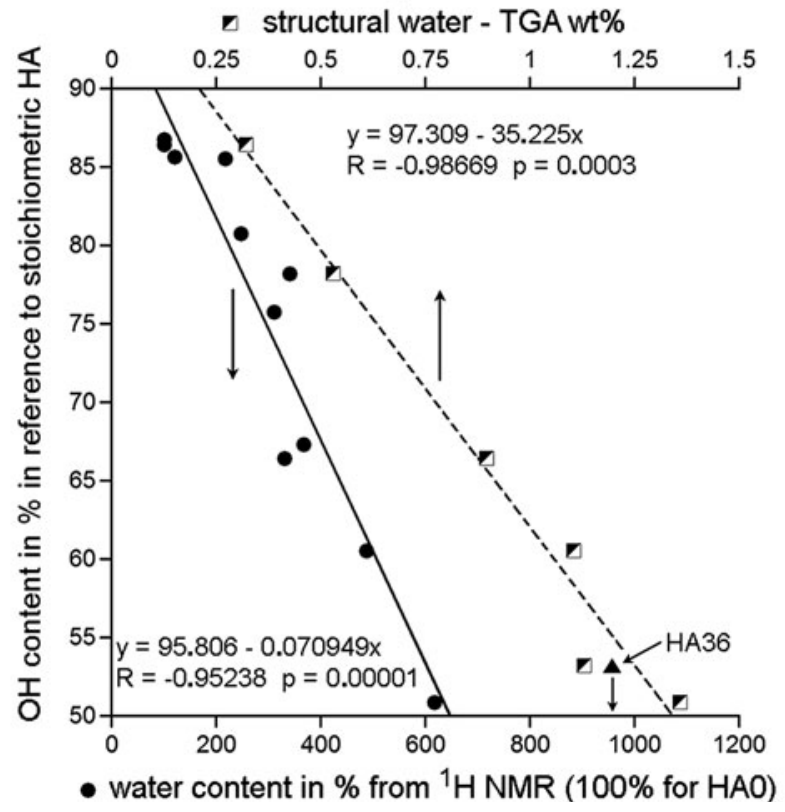

Fig. 8 The content of structural hydroxyl groups (in \% in reference to stoichiometric HA) plotted against following characteristics of the milled apatites: a FWHM of the narrow ${ }^{31} \mathrm{P}$ BD/MAS NMR component (MAS at $7 \mathrm{kHz}$ ) and FWHM of the ${ }^{1} \mathrm{H}$ MAS NMR hydroxyl peak (MAS at $12 \mathrm{kHz}$ ); b contribution of the broad component in $\%$ to the total ${ }^{31} \mathrm{P}$ BD/MAS

within and around the $c$-axis channels, according to the idea of Pasteris et al. (2004) and Wopenka and Pasteris (2005).
NMR signal area; c total and structural water contents from proton MAS NMR and TGA, respectively (see text). In the graph b points for MAS at 7.0 and $3.5 \mathrm{kHz}$ have been treated together, for the slower MAS rate first spinning sidebands were included in the deconvolutions and calculations

The reason of this disorder has been revealed by considering the dependence of the structural $\mathrm{OH}$ content on the amount of the hydrated apatite 
environments, monitored using the broad ${ }^{31} \mathrm{P}$ component area (Fig. 8b), and on the total water content $\left({ }^{1} \mathrm{H}\right.$ NMR) and the structural water content (TGA) (Fig. 8c). In all those cases we found significant negative linear correlations. They indicate that the studied disorder, diminishing the structural $\mathrm{OH}$ concentration, is probably caused by an uptake of the structural water into the $c$-axis apatite channels. Such explanation has already been given in our former work (Kaflak and Kolodziejski 2011). That water uptake should efficiently decrease the structural $\mathrm{OH}$ content particularly in the region underneath the apatite crystal surface. It is in accordance with the conclusion of Wilson et al. (2005) that "hydroxide ion is present in a limited portion of the crystal, most likely the internal region of the bone mineral crystallites and not near the disordered surface regions".

\section{Special case of sample HA36}

This sample had the smallest crystals (Table 1). We admit that the points for HA36 in several linear regression graphs were typical outliers. Comparing to HA24, HA36 contained less structural water (Fig. 6), less disordered water environments (Fig. 7c), more total water (Fig. 8c, cf. NMR estimation in Table 1) and slightly more structural $\mathrm{OH}$ groups (Table 1). It follows that HA36 had larger surface hydrated layer and lower concentration of structural water than expected from the milling time. We found that HA36 gave different EPR spectrum, generated using high energy $\gamma$-radiation (extra $\mathrm{O}^{-}$radicals located on the crystal surface, not present in other samples) (Sadło et al. 2012). As yet we have no idea why this sample did not match the whole series. We speculate that the reason had to be related to the exhausting milling.

\section{Conclusions}

Using the series of HA0-HA36 samples we carried out model ${ }^{1} \mathrm{H}$ and ${ }^{31} \mathrm{P}$ MAS NMR, TEM, and TGA studies of structural hydroxyl groups and water in dry-milled (up to $36 \mathrm{~h}$ ) apatites with various crystal sizes. The structural hydroxyl groups and water were monitored in the 130-30 $\mathrm{nm}$ range of the crystal length and in the 95-20 nm range of the crystal width (stubby rod-shaped crystals). Our work provides the following main conclusions:

(1) During milling the concentrations of structural $\mathrm{OH}$ groups and total water decreased and increased, respectively.

(2) The total water content increased with the decreasing mean crystal length and width because of an increasing surface area of crystallites.

(3) Water molecules were either adsorbed or structural, with their respective population ratio increasing from 0.6 for unmilled apatite to 2.3 for samples milled for 12-36 h. The adsorbed water was located in the surface hydrated layer and the structural water in the $c$-axis channels in the apatite crystal lattice.

(4) The surface hydrated layer began to take form typical of nanocrystalline apatites for crystallites ca. $80 \mathrm{~nm}$ long and $60 \mathrm{~nm}$ wide. For the lowest crystal sizes it contained ca. $30 \%$ of total apatite phosphorus.

(5) It has been found that molecules of the adsorbed water are capable of moving from the surface of apatite into its crystal lattice. This process is mediated by proton transfer involving water molecules and hydroxide ions in the $c$-axis channels, as proposed by Yoder et al. (2012a). Probably, there exists also physical diffusion of water molecules to fill voids in the $c$-axis channels.

(6) It was confirmed that the content of structural hydroxyl groups in nanocrystalline apatites decreases with the decreasing crystal size. For our samples this content decreased on milling by ca. $40 \%$ in reference to stoichiometric apatite, but it has not been reduced to the level of ca. $20 \%$, typical of nanocrystalline biological apatite of bone, dentin, and dental cementum.

(7) The reduction in the content of the structural hydroxyl groups was accompanied by a growing disorder within and around the $c$-axis channels, in accordance with the idea of Pasteris et al. (2004) and Wopenka and Pasteris (2005). We found that this disorder was caused by an uptake of the structural water into the $c$-axis apatite channels.

Acknowledgments The authors are grateful to the Polish Ministry of Science and Higher Education for financial support (Grant No. N N204 127037). The TEM studies were performed 
in the Laboratory of Electron Microscopy, Nencki Institute of Experimental Biology, Warsaw, Poland. We used equipment installed within the project sponsored by the EU Structural Funds: Centre of Advanced Technology BIM-Equipment purchase for the Laboratory of Biological and Medical Imaging.

Open Access This article is distributed under the terms of the Creative Commons Attribution License which permits any use, distribution, and reproduction in any medium, provided the original author(s) and the source are credited.

\section{References}

Abdel-Aal EA, El-Midany AA, El-Shall H (2008) Mechanochemical-hydrothermal preparation of nano-crystallite hydroxyapatite using statistical design. Mater Chem Phys 112(1):202-207. doi:10.1016/j.matchemphys.2008.05.053

Aoki H (ed) (1991) Science and medical applications of hydroxyapatite. Takayama Press, Tokyo

Bertinetti L, Tampieri A, Landi E, Ducati C, Midgley PA, Coluccia S, Martra G (2007) Surface structure, hydration, and cationic sites of nanohydroxyapatite: UHR-TEM, IR, and microgravimetric studies. J Phys Chem C 111(10):40274035. doi:10.1021/jp066040s

Bertinetti L, Tampieri A, Landi E, Bolis V, Busco C, Martra G (2008) Surface structure, hydration and cationic sites of nanohydroxyapatite. Key Eng Mater 361-363:87-90

Bignon A, Chevalier J, Fantozzi G (2002) Effect of ball milling on the processing of bone substitutes with calcium phosphate powders. J Biomed Mater Res (Appl Biomater) 63(5):619-626. doi:10.1002/jbm.10379

Bolis V, Busco C, Martra G, Bertinetti L, Sakhno Y, Ugliengo P, Chiatti F, Corno M, Roveri N (2012) Coordination chemistry of $\mathrm{Ca}$ sites at the surface of nanosized hydroxyapatite: interaction with $\mathrm{H}_{2} \mathrm{O}$ and CO. Philos Trans R Soc A 370(1963):1313-1336. doi:10.1098/rsta.2011.0273

Boskey AL (1997) Amorphous calcium phosphate: the contention of bone. J Dent Res 76(8):1433-1436

Cazalbou S, Combes C, Eichert D, Rey C (2004) Adaptative physico-chemistry of bio-related calcium phosphates. J Mater Chem 14(14):2148-2153. doi:10.1039/b401318b

Chaikina MV, Aman S (2005) Fracture, grinding, mechanical activation and synthesis processes in solids under mechanical action. Sci Sinter 37(2):93-105. doi:10.2298/ Sos0502093c

Chen Q, Hou SS, Schmidt-Rohr K (2004) A simple scheme for probehead background suppression in one-pulse ${ }^{1} \mathrm{H}$ NMR. Solid State Nucl Magn Reson 26(1):11-15. doi:10.1016/j. ssnmr.2003.08.002

Cho G, Wu Y, Ackerman JL (2003) Detection of hydroxyl ions in bone mineral by solid-state NMR spectroscopy. Science 300(5622):1123-1127. doi:10.1126/science. 1078470

Combes C, Rey C (2010) Amorphous calcium phosphates: synthesis, properties and uses in biomaterials. Acta Biomater 6(9):3362-3378. doi:10.1016/j.actbio.2010.02.017

Dorozhkin SV (2009) Calcium orthophosphates in nature, biology and medicine. Materials 2(2):399-498
Dorozhkin SV (2010) Nanosized and nanocrystalline calcium orthophosphates. Acta Biomater 6(3):715-734. doi: 10.1016/j.actbio.2009.10.031

Eichert D, Drouet C, Sfihi H, Rey C, Combes C (eds) (2009) Nanocrystalline apatite-based biomaterials. Nova Science Publishers, Inc., New York

Elliott JC (1994) Structure and chemistry of the apatites and other calcium orthophosphates. Studies in inorganic chemistry, vol 18. Elsevier, Amsterdam

Glazner AF, Mills RD (2012) Interpreting two-dimensional cuts through broken geologic objects: fractal and non-fractal size distributions. Geosphere 8(4):902-914. doi:10.1130/ ges00731.1

Higgins MD (2000) Measurement of crystal size distributions. Am Mineral 85(9):1105-1116

Ishikawa T, Wakamura M, Kondo S (1989) Surface characterization of calcium hydroxylapatite by Fourier transform infrared spectroscopy. Langmuir 5(1):140-144

Isobe T, Nakamura S, Nemoto R, Senna M, Sfihi H (2002) Solid-state double nuclear magnetic resonance study of the local structure of calcium phosphate nanoparticles synthesized by a wet-mechanochemical reaction. J Phys Chem B 106(20):5169-5176. doi:10.1021/jp0138936

Ivanova TI, Frank-Kamenetskaya OV, Kol'tsov AB, Ugolkov VL (2001) Crystal structure of calcium-deficient carbonated hydroxyapatite. Thermal decomposition. J Solid State Chem 160(2):340-349. doi:10.1006/jssc.2000.9238

Jäger C, Maltsev S, Karrasch A (2006a) Progress of structural elucidation of amorphous calcium phosphate (ACP) and hydroxyapatite (HAp): disorder and surfaces as seen by solid state NMR. Key Eng Mater 309-311:69-72

Jäger C, Welzel T, Meyer-Zaika W, Epple M (2006b) A solidstate NMR investigation of the structure of nanocrystalline hydroxyapatite. Magn Reson Chem 44(6):573-580. doi:10. 1002/mrc. 1774

Jarlbring M, Sandström DE, Antzutkin ON, Forsling W (2006) Characterization of active phosphorus surface sites at synthetic carbonate-free fluorapatite using single-pulse ${ }^{1} \mathrm{H}$, ${ }^{31} \mathrm{P}$, and ${ }^{31} \mathrm{P}$ CP MAS NMR. Langmuir 22(10):4787-4792. doi: $10.1021 / 1 a 052837 \mathrm{j}$

Kaflak A, Kolodziejski W (2007) Phosphorus-31 spin-lattice NMR relaxation in bone apatite and its mineral standards. Solid State Nucl Magn Reson 31(4):174-183. doi:10.1016/ j.ssnmr.2007.04.005

Kaflak A, Kolodziejski W (2008) Kinetics of ${ }^{1} \mathrm{H} \rightarrow{ }^{31} \mathrm{P}$ NMR cross-polarization in bone apatite and its mineral standards. Magn Reson Chem 46(4):335-341. doi:10.1002/mrc.2207

Kaflak A, Kolodziejski W (2011) Complementary information on water and hydroxyl groups in nanocrystalline carbonated hydroxyapatites from TGA, NMR and IR measurements. J Mol Struct 990(1-3):263-270. doi:10.1016/j. molstruc.2011.01.056

Kaflak A, Ślósarczyk A, Kolodziejski W (2011) A comparative study of carbonate bands from nanocrystalline carbonated hydroxyapatites using FT-IR spectroscopy in the transmission and photoacoustic modes. J Mol Struct 997(1-3):7-14. doi:10.1016/j.molstruc.2011.04. 013

Kaflak-Hachulska A (2000) A study of bone mineral using NMR spectroscopy with cross-polarization. $\mathrm{PhD}$ thesis, Medical University of Warsaw, Warsaw 
Kaflak-Hachulska A, Samoson A, Kolodziejski W (2003) ${ }^{1} \mathrm{H}$ MAS and ${ }^{1} \mathrm{H} \rightarrow{ }^{31} \mathrm{P}$ CP/MAS NMR study of human bone mineral. Calcif Tissue Int 73(5):476-486. doi:10.1007/ s00223-002-2111-5

Kolmas J, Kolodziejski W (2007) Concentration of hydroxyl groups in dental apatites: a solid-state ${ }^{1} \mathrm{H}$ MAS NMR study using inverse ${ }^{31} \mathrm{P} \rightarrow{ }^{1} \mathrm{H}$ cross-polarization. Chem Commun 42:4390-4392. doi:10.1039/b708317c

Kolodziejski W (2005) Solid-state NMR studies of bone. Top Curr Chem 246:235-270

Kolodziejski W, Klinowski J (2002) Kinetics of cross-polarization in solid-state NMR: a guide for chemists. Chem Rev 102(3):613-628. doi:10.1021/cr000060n

Landi E, Tampieri A, Celotti G, Sprio S (2000) Densification behaviour and mechanisms of synthetic hydroxyapatites. J Eur Ceram Soc 20(14-15):2377-2387. doi:10.1016/ s0955-2219(00)00154-0

LeGeros RZ (1991) Calcium phosphates in oral biology and medicine. Monogr Oral Sci 15:1-201

Mason HE, McCubbin FM, Smirnov AE, Phillips BL (2009) Solid-state NMR and IR spectroscopic investigation of the role of structural water and $\mathrm{F}$ in carbonate-rich fuorapatite. Am Mineral 94(4):507-516. doi:10.2138/am.2009.3095

Mohammadi Zahrani E, Fathi MH (2009) The effect of highenergy ball milling parameters on the preparation and characterization of fluorapatite nanocrystalline powder. Ceram Int 35(6):2311-2323. doi:10.1016/j.ceramint.2009. 01.012

Nakano T, Tokumura A, Umakoshi Y, Imazato S, Ehara A, Ebisu S (2001) Control of hydroxyapatite crystallinity by mechanical grinding method. J Mater Sci: Mater Med 12(8):703-706. doi:10.1023/a:1011220610008

Nasiri-Tabrizi B, Honarmandi P, Ebrahimi-Kahrizsangi R (2009) Synthesis of nanosize single-crystal hydroxyapatite via mechanochemical method. Mater Lett 63(5):543-546. doi:10.1016/j.matlet.2008.11.030

Nilpairach S (1997) Effect of wet and dry milling on properties of sintered hydroxyapatite. J Met Mater Miner 7(1):45-49

Nordström EG, Karlsson KH (1990) Carbonate-doped hydroxyapatite. J Mater Sci: Mater Med 1(3):182-184. doi:10.1007/bf00700880

Olszta MJ, Cheng X, Jee SS, Kumar R, Kim YY, Kaufman MJ, Douglas EP, Gower LB (2007) Bone structure and formation: a new perspective. Mater Sci Eng, R 58(3-5): 77-116. doi:10.1016/j.mser.2007.05.001

Pasteris JD, Wopenka B, Freeman JJ, Rogers K, Valsami-Jones E, Van Der Houwen JAM, Silva MJ (2004) Lack of OH in nanocrystalline apatite as a function of degree of atomic order: implications for bone and biomaterials. Biomaterials 25(2):229-238. doi:10.1016/s0142-9612(03)00487-3

Ramirez CAO, Costa AM, Bettini J, Ramirez AJ, Da Silva MHP, Rossi AM (2009) Structural properties of nanostructured carbonate apatites. Key Eng Mater 396398:611-614
Rey C, Combes C, Drouet C, Sfihi H, Barroug A (2007) Physicochemical properties of nanocrystalline apatites: implications for biominerals and biomaterials. Mater Sci Eng, C 27(2):198-205. doi:10.1016/j.msec.2006.05.015

Rey C, Combes C, Drouet C, Glimcher MJ (2009) Bone mineral: update on chemical composition and structure. Osteoporos Int 20(6):1013-1021. doi:10.1007/s00198-009-0860-y

Royet J-P (1991) Stereology: a method for analyzing images. Prog Neurobiol 37(5):433-474. doi:http://dx.doi.org/10. 1016/0301-0082(91)90009-P

Ruksudjarit A, Pengpat K, Rujijanagul G, Tunkasiri T (2008) Synthesis and characterization of nanocrystalline hydroxyapatite from natural bovine bone. Curr Appl Phys 8(3-4):270-272. doi:10.1016/j.cap.2007.10.076

Sadło J, Pajchel L, Michalik J, Kolodziejski W (2012) EPR studies of radicals generated by $\gamma$-radiation in nanocrystalline hydroxyapatites prepared by dry milling. J Mol Struct 1012(0):61-67. doi:10.1016/j.molstruc.2012.04.062

Sakhno Y, Bertinetti L, Iafisco M, Tampieri A, Roveri N, Martra G (2010) Surface hydration and cationic sites of nanohydroxyapatites with amorphous or crystalline surfaces: a comparative study. J Phys Chem C 114(39):16640-16648. doi:10.1021/jp105971s

Sønju Clasen AB, Ruyter IE (1997) Quantitative determination of type A and type B carbonate in human deciduous and permanent enamel by means of Fourier transform infrared spectrometry. Adv Dent Res 11(4):523-527

Turcotte DL (1986) Fractals and fragmentation. J Geophys Res: Solid Earth 91(B2):1921-1926. doi:10.1029/JB091iB02 p01921

Wilson EE, Awonusi A, Morris MD, Kohn DH, Tecklenburg MM, Beck LW (2005) Highly ordered interstitial water observed in bone by nuclear magnetic resonance. J Bone Miner Res 20(4):625-634. doi:10.1359/JBMR.041217

Wilson EE, Awonusi A, Morris MD, Kohn DH, Tecklenburg MM, Beck LW (2006) Three structural roles for water in bone observed by solid-state NMR. Biophys J 90(10): 3722-3731. doi:10.1529/biophysj.105.070243

Wopenka B, Pasteris JD (2005) A mineralogical perspective on the apatite in bone. Mater Sci Eng, C 25(2):131-143. doi:10.1016/j.msec.2005.01.008

Wu Y, Glimcher MJ, Rey C, Ackerman JL (1994) A unique protonated phosphate group in bone mineral not present in synthetic calcium phosphates. Identification by phosphorus-31 solid state NMR spectroscopy. J Mol Biol 244(4): 423-435. doi:10.1006/jmbi.1994.1740

Yoder C, Pasteris J, Worcester K, Schermerhorn D, Sternlieb M, Goldenberg J, Wilt Z (2012a) Dehydration and rehydration of carbonated fluor- and hydroxylapatite. Minerals 2(2): $100-117$

Yoder CH, Pasteris JD, Worcester KN, Schermerhorn DV (2012b) Structural water in carbonated hydroxylapatite and fluorapatite: confirmation by solid state ${ }^{2} \mathrm{H}$ NMR. Calcif Tissue Int 90(1):60-67. doi:10.1007/s00223-011-9542-9 